\title{
The development of a real-time PCR assay for the diagnosis of a broad range of fungal infections
}

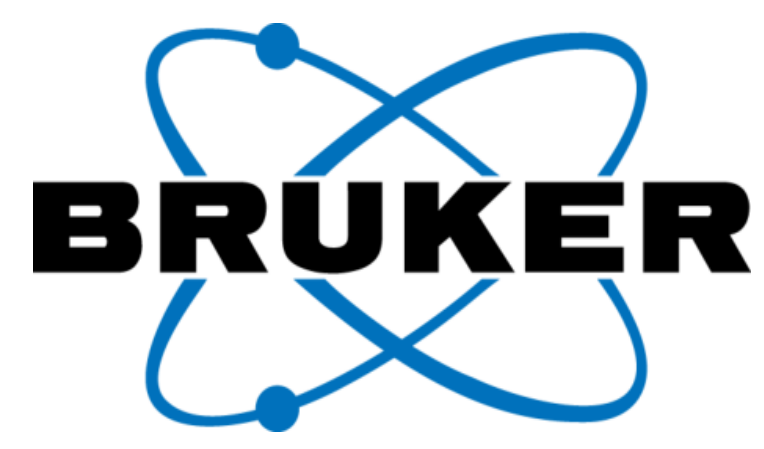

Selina Henriquez, Kate Dempsey, Colette Dalton, Tara Donnelly \& Julie Green* Bruker Microbiology, Glasgow, UK julie.green@bruker.com

\section{Introduction}

Invasive fungal diseases (IFDs) are a significant cause of morbidity and mortality in patients who are immunocompromised or undergoing intensive therapy. The diagnosis of IFDs is challenging as clinical manifestations are non-specific and standard methods of diagnosis are often slow or have low sensitivity. In recent years, the epidemiology of IFDs has changed; Candida species remain the most common causes of IFD, but the incidence of Aspergillus species and other filamentous fungi, such as Zygomycetes, Fusarium and Scedosporium spp. has increased. ${ }^{1}$ Identifying a fungal infection as early as possible is critical for implementing appropriate antifungal therapy; early diagnosis can improve treatment outcomes and potentially reduce healthcare costs. ${ }^{2}$

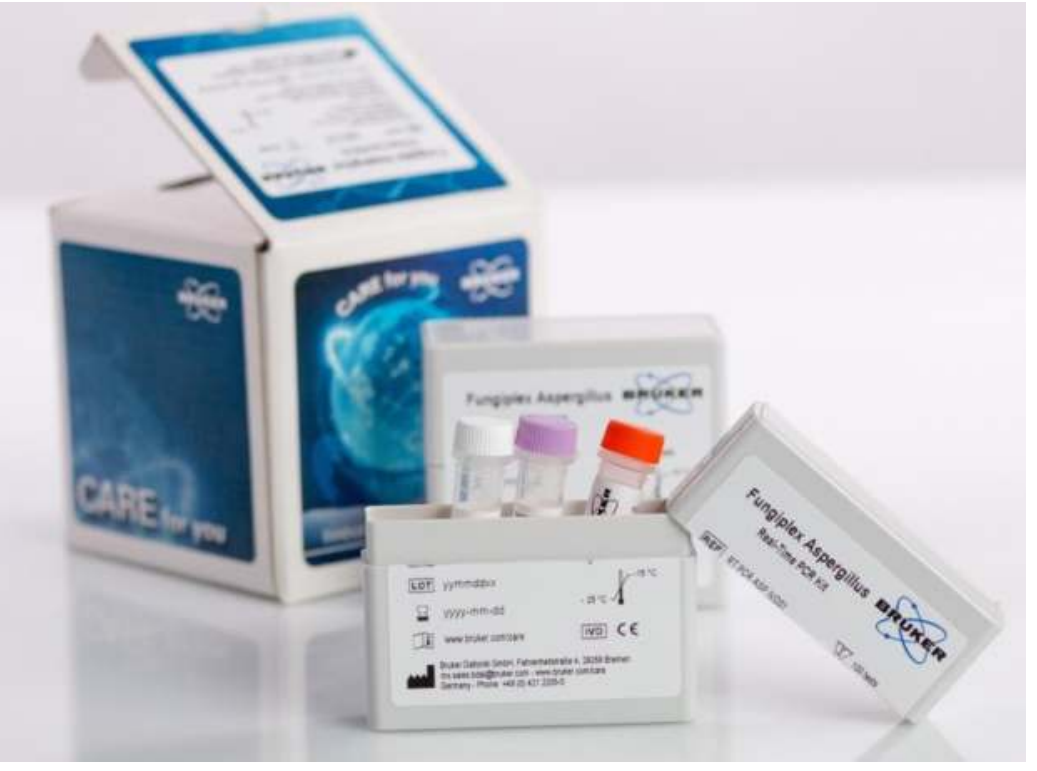

Fig 1: Example of a Fungiplex Real-Time PCR Kit

The Fungiplex ${ }^{\oplus}$ Universal RUO PCR Kit provides a multiplex polymerase chain reaction (PCR) test for the rapid detection of fungal species in various sample matrices, such as whole blood, serum, plasma, bronchoalveolar lavage (BAL) and directly from isolates. This test is for research use only and covers a broad range of fungal pathogens providing rapid results with high sensitivity and specificity without isolation of the organism (Table 1).

The Fungiplex Universal RUO PCR Kit is validated to detect fungal species not detected by other diagnostic biomarkers, such as from the Zygomycetes or Cryptococcus genera.

Table 1: Genera detected by the Fungiplex Universal RUO PCR Kit

\begin{tabular}{|c|c|c|}
\hline Apophysomyces & Fusarium & Rhizomucor \\
\hline Aspergillus & Histoplasma & Rhizopus \\
\hline Candida & Lichtheimia & Saccharomyces \\
\hline Cladosporium & Microsporum & Saksenaea \\
\hline Coccidioides & Mucor & Scedosporium \\
\hline Cryptococcus & Paecilomyces & Syncephalastrum \\
\hline Cunninghamella & Penicillium & Talaromyces \\
\hline Exophiala & Pneumocystis & Trichosporon \\
\hline
\end{tabular}

\section{Methods}

Primers and probes were designed to detect the ribosomal RNA gene internal transcribed spacer region which was found to be highly specific.

The analytical performance of the Fungiplex Universal assay was determined by testing plasmid material to determine the Limit of Detection (LOD) and performance across a dynamic range $\left(20-2 \times 10^{6}\right.$ input copies). Cross-reactivity studies were carried out as well as testing the assay robustness to inhibitors.

Simulated samples were prepared by spiking known concentrations of plasmid \& gDNA for a variety of fungal species into serum, plasma and BAL. Extractions were performed on the Qiagen EZ1 platform.

\section{Results}

The LOD of plasmid DNA for 50 different fungal species targets was determined on five real-time PCR instruments with example data shown (Table 2). The overall sensitivity and specificity of the Fungiplex Universal RUO PCR assay has been reported (Table 3).

Table 2: Limit of detection data for example targets tested across 5 real-time PCR instruments

\begin{tabular}{|c|c|c|c|c|c|}
\hline $\begin{array}{c}\text { Fungiplex Universal } \\
\text { Target }\end{array}$ & \multicolumn{5}{|c|}{ LOD (ipc / rxn) per instrument } \\
\hline Aspergillus fumigatus & 50 & LC480 II & QuantStudio & AB17500 & RotorGene \\
\hline Apophomyces elegans & 50 & 100 & 50 & 50 & 50 \\
\hline Cryptococcus neoformans & 50 & 100 & 50 & 50 & 50 \\
\hline Trichosporon asahii & 100 & 200 & 200 & 200 & 100 \\
\hline Lichtheimia corybifera & 50 & 50 & 50 & 50 & 50 \\
\hline Mucor circinelloides & 50 & 50 & 50 & 50 & 50 \\
\hline Rhizomucor pusillus & 50 & 50 & 50 & 50 & 50 \\
\hline Syncephalastrum & 50 & 50 & 50 & 50 & 50 \\
\hline racemosum & 300 & 200 & 200 & 200 & 200 \\
\hline Pneumocystis jirovecii & 30 & & & & \\
\hline
\end{tabular}

Table 3: Detection rates at the defined LOD for a selection of plasmid and gDNA

\begin{tabular}{|c|c|c|c|c|c|c|}
\hline $\begin{array}{l}\text { Fungiplex Universal } \\
\text { Target }\end{array}$ & CFX & $\begin{array}{l}\text { Quant } \\
\text { Studio }\end{array}$ & $\begin{array}{c}\text { LC } 480 \\
\text { II }\end{array}$ & ABI7500 & $\begin{array}{l}\text { Rotor- } \\
\text { Gene }\end{array}$ & $\begin{array}{l}\text { All } \\
\text { thermal } \\
\text { cyclers }\end{array}$ \\
\hline Aspergillus fumigatus & $32 / 32$ & $16 / 16$ & $16 / 16$ & $16 / 16$ & $16 / 16$ & $96 / 96$ \\
\hline Apophysomyces elegans & $30 / 32$ & $16 / 16$ & $16 / 16$ & $16 / 16$ & $16 / 16$ & $94 / 96$ \\
\hline Cryptococcus neoformans & $32 / 32$ & $16 / 16$ & $16 / 16$ & $16 / 16$ & $16 / 16$ & $96 / 96$ \\
\hline Trichosporon asahii & $16 / 16$ & $16 / 16$ & $32 / 32$ & $16 / 16$ & $16 / 16$ & $96 / 96$ \\
\hline Lichtheimia corymbifera & $16 / 16$ & $16 / 16$ & $31 / 32$ & $16 / 16$ & $16 / 16$ & $95 / 96$ \\
\hline Mucor circinelloides & $16 / 16$ & $16 / 16$ & $31 / 32$ & $16 / 16$ & $16 / 16$ & 95/96 \\
\hline Rhizomucor pusillus & $16 / 16$ & $32 / 32$ & $16 / 16$ & $16 / 16$ & $16 / 16$ & $96 / 96$ \\
\hline $\begin{array}{l}\text { Syncephalastrum } \\
\text { racemosum }\end{array}$ & $16 / 16$ & $30 / 32$ & $15 / 16$ & $16 / 16$ & $16 / 16$ & $94 / 96$ \\
\hline Pneumocystis jirovecii & $16 / 16$ & $32 / 32$ & $16 / 16$ & $16 / 16$ & $16 / 16$ & $96 / 96$ \\
\hline Trichosporon asahii gDNA & $\begin{array}{c}\text { Not } \\
\text { Tested }\end{array}$ & $\begin{array}{c}\text { Not } \\
\text { Tested }\end{array}$ & Not Tested & Not Tested & $16 / 16$ & $16 / 16$ \\
\hline Mucor circinelloides gDNA & $\begin{array}{l}\text { Not } \\
\text { Tested }\end{array}$ & $\begin{array}{l}\text { Not } \\
\text { Tested }\end{array}$ & Not Tested & Not Tested & $16 / 16$ & $16 / 16$ \\
\hline Rhizopus oryzae gDNA & $\begin{array}{l}\text { Not } \\
\text { Tested }\end{array}$ & $\begin{array}{l}\text { Not } \\
\text { Tested }\end{array}$ & Not Tested & $16 / 16$ & $\begin{array}{l}\text { Not } \\
\text { Tested }\end{array}$ & $16 / 16$ \\
\hline Candida albicans gDNA & $\begin{array}{l}\text { Not } \\
\text { Tested }\end{array}$ & $\begin{array}{l}\text { Not } \\
\text { Tested }\end{array}$ & Not Tested & $16 / 16$ & $\begin{array}{l}\text { Not } \\
\text { Tested }\end{array}$ & $16 / 16$ \\
\hline $\begin{array}{c}\text { Cryptococcus neoformans } \\
\text { gDNA }\end{array}$ & $\begin{array}{l}\text { Not } \\
\text { Tested }\end{array}$ & $\begin{array}{l}\text { Not } \\
\text { Tested }\end{array}$ & Not Tested & $16 / 16$ & $\begin{array}{l}\text { Not } \\
\text { Tested }\end{array}$ & $16 / 16$ \\
\hline Total Number of Samples & 192 & 192 & 192 & 192 & 176 & 944 \\
\hline Assay sensitivity (\%) & 98.3 & 100.0 & 97.5 & 100.0 & 100.0 & 99.1 \\
\hline Assay specificity (\%) & 98.2 & 99.5 & 99.7 & 99.2 & 97.4 & 98.8 \\
\hline
\end{tabular}

\section{Conclusions}

- Fungiplex Universal reliably detects fungal DNA from genera not identified using (1-3)-beta-D-glucan assays

- Analytical sensitivity and specificity was $>\mathbf{9 7} \%$ when tested with a broad range of fungal pathogens

- The Fungiplex Universal RUO Real Time PCR can be used when the presence of fungal species is suspected

\section{References}

(1) Ala-Houhala M et al., Clinical Microbiology and Infection 2017; 1-5.

(2) Drgona L et al., European Journal of Clinical Microbiology \& Infectious Disease 2014; 33: 7-21. 